\title{
Impact of Incident Cancer on Short-Term Coronary Artery Disease-Related Healthcare Expenditures Among Medicare Beneficiaries
}

Ishveen Chopra, PhD, MBA; Malcolm D. Mattes, MDª Patricia Findley, DrPH, MSW, LCSWc; Xi Tan, PharmD, PhDa; Nilanjana Dwibedi, MBA, PhD; and Usha Sambamoorthi, $\mathrm{PhD}^{\mathrm{a}}$

\begin{abstract}
Background: Healthcare spending for coronary artery disease (CAD)-related services is higher than for other chronic conditions. Diagnosis of incident cancer may impede management of CAD, thereby increasing the risk of CAD-related complications and associated healthcare expenditures. This study examined the relationship between incident cancer and CAD-related expenditures among elderly Medicare beneficiaries. Patients and Methods: A retrospective longitudinal study was conducted using the SEER-Medicare linked registries and a $5 \%$ noncancer random sample of Medicare beneficiaries. Elderly fee-for-service Medicare beneficiaries with preexisting $\mathrm{CAD}$ and with incident breast, colorectal, or prostate cancer $(N=12,095)$ or no cancer $(N=34,237)$ were included. CADrelated healthcare expenditures comprised Medicare payments for inpatient, home healthcare, and outpatient services. Expenditures were measured every 120 days during the 1-year preindex and 1-year postindex periods. Adjusted relationship between incident cancer and expenditures was analyzed using the generalized linear mixed models. Results: Overall, CAD-related mean healthcare expenditures in the preindex period accounted for approximately $32.6 \%$ to $39.5 \%$ of total expenditures among women and $41.5 \%$ to $46.8 \%$ among men. All incident cancer groups had significantly higher CADrelated expenditures compared with noncancer groups $(P<.0001)$. Men and women with colorectal cancer (CRC) had 166\% and 153\% higher expenditures, respectively, compared with their noncancer counterparts. Furthermore, men and women with CRC had $57 \%$ and $55 \%$ higher expenditures compared with those with prostate or breast cancer, respectively. Conclusions: CAD-related expenditures were higher for elderly Medicare beneficiaries with incident cancer, specifically for those with CRC. This warrants the need for effective programs and policies to reduce CAD-related expenditures. Close monitoring of patients with a cancer diagnosis and preexisting CAD may prevent CAD-related events and expenditures.
\end{abstract}

J Natl Compr Canc Netw 2019;17(2):149-158 doi: $10.6004 /$ jnccn.2018.7078

\footnotetext{
aDepartment of Pharmaceutical Systems and Policy, West Virginia University, and ${ }^{b}$ Department of Medical Education, WVU School of Medicine,

Morgantown, West Virginia; and 'School of Social Work, Rutgers University,
} New Brunswick, New Jersey.

\section{Background}

Cardiovascular disease, including coronary artery disease (CAD) and cerebrovascular disease, has the highest healthcare expenditures $\left(\sim 231.1\right.$ billion in 2013). ${ }^{1}$ Healthcare spending for CAD-related services is higher than that for other chronic conditions. ${ }^{2-4}$ Furthermore, CAD-related healthcare expenditures in the United States are projected to increase $198 \%$ by 2030 because of the aging population. ${ }^{2}$

Evidence also suggests that individuals with $\mathrm{CAD}$ have many preexisting conditions or may develop new conditions. The most common preexisting or existing conditions in patients with CAD include cancer, hypertension, diabetes, and other cardiovascular diseases. ${ }^{5}$ For these individuals, CAD-related expenditures can be higher than for those who only have CAD. ${ }^{4,6}$ Specifically, CAD-related expenditures may be higher among individuals with incident cancer (and CAD) during the period immediately after cancer diagnosis, because cardiotoxicity from specific cancer treatments can exacerbate preexisting $\mathrm{CAD},{ }^{7,8}$ and diagnosis of incident cancer may impede management of $\mathrm{CAD}$, thereby increasing the risk of CAD-related complications, given that cancer is considered a dominant condition. ${ }^{9}$

However, there is a dearth of studies on the impact of incident cancer diagnosis on CAD-related expenditures. It is important to analyze CAD-related expenditures among Medicare beneficiaries because there are significant differences in healthcare expenditures directly attributed to CAD and total expenditures associated with $\mathrm{CAD}^{2}{ }^{2}$ Specifically, published studies suggest that inpatient spending accounts for nearly $43 \%$ of total expenditures for cardiovascular diseases. ${ }^{10}$ Furthermore, CAD-related expenditures may be higher among elderly individuals (aged $\geq 65$ years) as a result of comorbidities related to aging. For example, Dieleman et $\mathrm{al}^{1}$ reported

See JNCCN.org for supplemental online content. 
that $65.2 \%$ of expenditures for $\mathrm{CAD}$ and related diseases were for elderly individuals, suggesting that these individuals account for most of the expenditures associated with CAD care. Because nearly $84 \%$ of elderly patients are covered by Medicare, ${ }^{11}$ payments made by Medicare for $\mathrm{CAD}$ are substantial, suggesting that it is important to estimate Medicare payments for CAD care. In 2012, Medicare paid \$273 billion for heart disease-related expenditures, with a per-person cost of $\$ 10,345 .{ }^{12}$

Estimating the extent to which incident cancer affects CAD-related expenditures can help payers with emerging healthcare delivery reform initiatives. These initiatives are focused on financial incentives to improve healthcare quality with lower expenditures. For example, new payment models from the Centers for Medicare \& Medicaid Services (CMS) support bundled payments for episodes of care. One experimental initiative will support bundled payments for clinicians providing care to patients with CAD. ${ }^{13}$ Such models have the potential to be extended to individuals who develop cancer after CAD. For example, the Medicare Access and CHIP Reauthorization Act of 2015 (MACRA) created alternative payment models, ${ }^{13}$ providing value-based care and penalties for poor quality of care. These models require risk adjustment for patients, ${ }^{14-16}$ and therefore identifying those at risk for high cost is important.

The present study examined the impact of incident cancer on CAD-related expenditures using data from a cohort of elderly fee-for-service (FFS) Medicare beneficiaries with and without cancer. The cancer cohort consisted of elderly patients with incident breast, colorectal, or prostate cancer. These cancers were selected because they have a higher prevalence among the elderly population, ${ }^{17}$ and preexisting CAD is highly prevalent in this population diagnosed with these cancers. ${ }^{18-23}$

\section{Patients and Methods}

\section{Conceptual Framework}

The conceptual framework of this study was adapted based on Andersen's Behavioral Model of Health Service Use for understanding CAD-related healthcare expenditures and a priori selection of independent variables. $^{24,25}$ This model posits that an individual's predisposing, enabling, and need factors; personal health practices; healthcare use; and external environment may influence healthcare expenditures. ${ }^{26}$

\section{Study Design}

A retrospective observational longitudinal cohort design with 12-month preindex and postindex periods was used. Index date was defined as the date of incident cancer diagnosis for the cancer cohort and pseudo-diagnosis date for the noncancer cohort. Pseudo-diagnosis dates

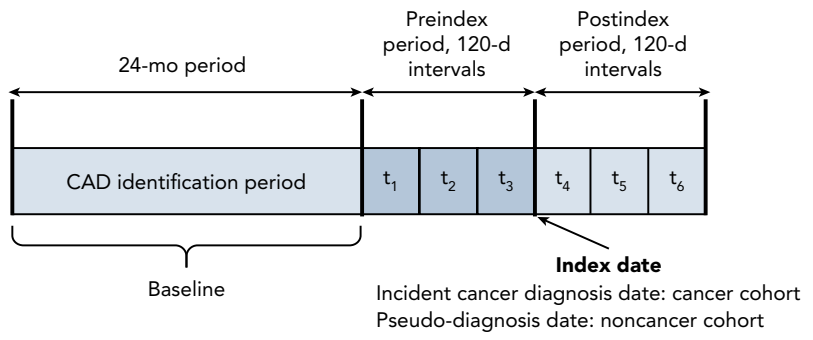

Figure 1. Schematic of the study design. Each individual was observed for 48 months with a 24-month baseline (for identification of CAD and baseline characteristics), 12-month preindex, and 12-month postindex period. CAD-related healthcare expenditures and selected independent variables were measured repeatedly every 120 days during the preindex $\left(t_{1}, t_{2}\right.$, and $\left.t_{3}\right)$ and postindex $\left(t_{4}, t_{5}\right.$, and $\left.t_{6}\right)$ periods, yielding a total of 6 repeated measures for every individual. Abbreviation: CAD, coronary artery disease.

were randomly selected from the dates of service. Each individual was observed for 48 months (Figure 1).

\section{Data Sources}

Data were derived from claims in the SEER-Medicare linked registries, $5 \%$ noncancer random sample of Medicare beneficiaries in the SEER region (living in the same SEER areas as those in the cancer registry), American Community Survey (census tract information), ${ }^{27}$ and the Area Health Resources Files (countylevel healthcare environment factors). ${ }^{28}$

\section{Study Population}

The study population comprised beneficiaries with preexisting CAD, who were further categorized into those with incident breast, colorectal, or prostate cancer and those without cancer. The cancer cohort comprised the total number of incident cases and not the random sample. CAD was identified using a validated algorithm developed by $\mathrm{CMS}^{29}$ that used ICD-9-CM codes. Individuals with at least 2 inpatient, outpatient, and carrier claims (clinician encounters only), or home healthcare agency (HHA) service Medicare claims with a primary or secondary diagnosis of CAD during the baseline were classified as preexisting CAD. Incident cancer, defined as new cancer diagnosis during the study period (January 2008 through December 2011), was identified using the ICD-O-3 codes from the SEER registries.

Other inclusion criteria were age $\geq 68$ years, alive with continuous FFS Medicare Parts A and B enrollment during the entire study period, continuous Part D enrollment during the preindex and postindex periods, no missing information on county, and total expenditures $>\$ 0$ during the preindex and postindex periods. In the cancer cohort, individuals with missing data on cancer type and stage and those diagnosed postmortem were excluded (Figure 2). 

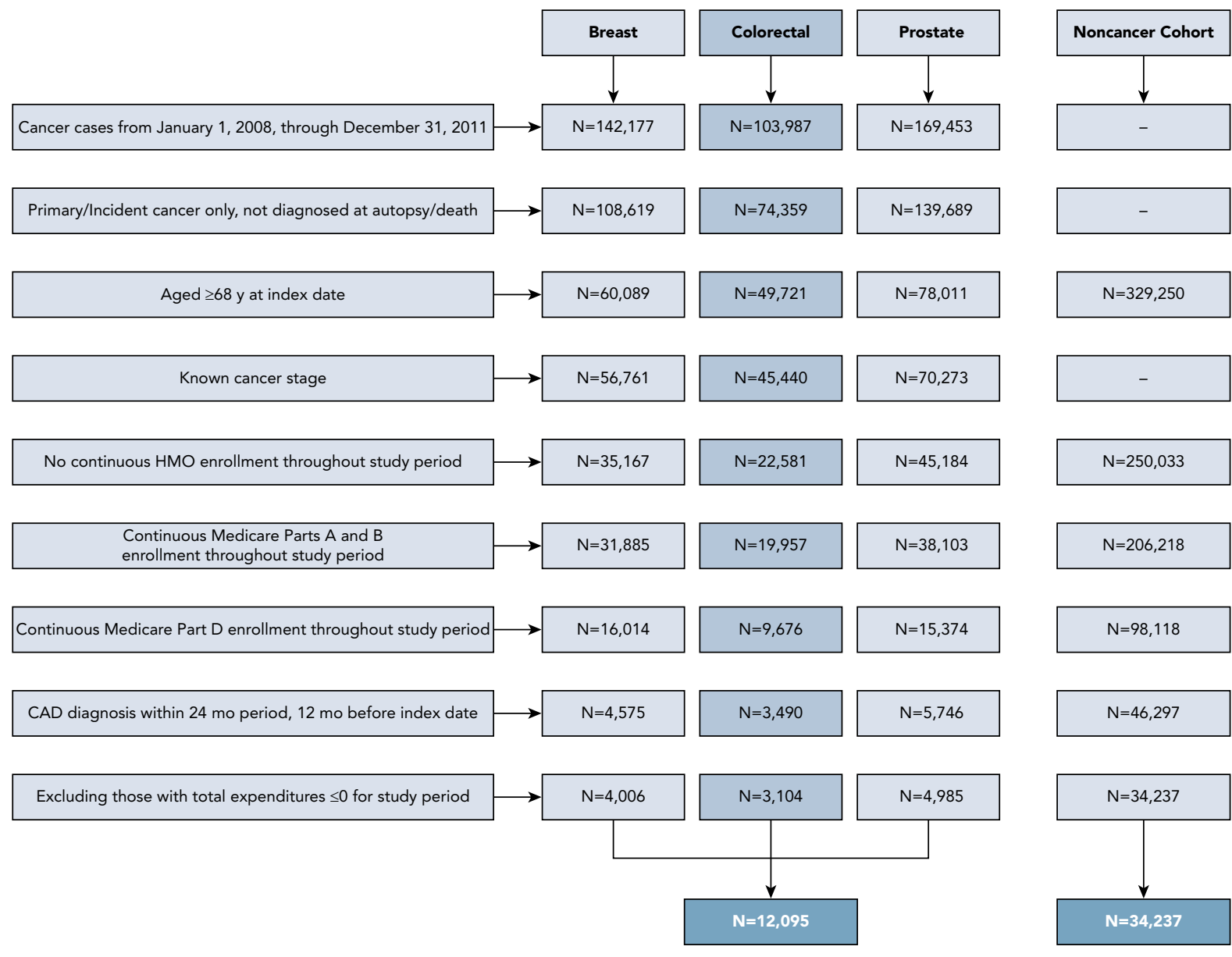

Figure 2. Schematic presentation of selection criteria for study cohort. Abbreviation: $C A D$, coronary artery disease.

\section{Measures}

\section{Dependent Variable: CAD-Related Expenditures}

CAD-related healthcare and total expenditures consisted of Medicare payments for inpatient, HHA, and outpatient services for CAD-related care, measured every 120 days $\left(t_{1}, t_{2}, t_{3}, t_{4}, t_{5}\right.$, and $\left.t_{6}\right)$. CAD-related services were identified using ICD-9-CM primary and secondary diagnosis codes for CAD. ${ }^{30,31}$ Prescription medication and durable medical equipment (DME) expenditures were not included because of the challenges in identifying CAD-related expenditures in DME and prescription drug claims. Short-term healthcare expenditures $>12$ months in the postindex period were examined. Healthcare expenditures were adjusted by the Consumer Price Index for medical services ${ }^{32}$ and expressed in 2012 USD.

\section{Key Independent Variables: Sex and Cancer Type}

Because the study included women with breast cancer and men with prostate cancer, the key time-invariant independent variable accounted for both sex and cancer type and was categorized into 6 mutually exclusive groups: women with breast cancer, women with colorectal cancer (CRC), women with no cancer, men with prostate cancer, men with CRC, and men with no cancer.

\section{Other Independent Variables}

Predisposing Factors

Age measured at index month of incident cancer diagnosis and race/ethnicity were time-invariant independent variables.

\section{Enabling Factors}

Medicare Part D coverage gap (measured every 120 days) and census tract-level education attainment and poverty status (based on income threshold that varied by family size and composition; measured at baseline).

\section{Need-Based Factors}

Physical health conditions were measured at baseline and categorized into concordant (cardiac arrhythmias, 
congestive heart failure, diabetes, hyperlipidemia, hypertension, and stroke) and discordant (dementia, asthma, chronic obstructive pulmonary disease, arthritis, hepatitis, HIV, and osteoporosis). Mental health conditions included severe mental illness (schizophrenia, bipolar disorder, and psychoses; measured at baseline), anxiety, and depression (measured every 120 days). For CAD severity, a proxy measure, which was measured at baseline, was constructed based on the CMS hierarchical condition category (HCC) classification system, in which each of the HCC codes for CAD was assigned a specific score based on the risk and severity, ranging from 0.231 to 0.349 . Higher scores represented severe manifestations of CAD. ${ }^{33}$

Personal Healthcare Practices

Tobacco and alcohol abuse ${ }^{34,35}$ were measured every 120 days.

\section{Healthcare Use}

Primary care visits, cardiologist visits, and adherence to statins or angiotensin converting enzyme inhibitors (ACEIs), angiotensin II receptor blockers (ARBs), or $\beta$-blockers measured every 120 days. Adherence was defined as proportion of days covered (PDC), calculated among those who filled $\geq 2$ prescriptions for either statins or any 2 prescriptions of ACEIs/ARBs/ $\beta$-blockers. Individuals with $\mathrm{PDC} \geq 80 \%$ were considered adherent and those with PDC $<80 \%$ were considered nonadherent. ${ }^{36}$ PDC measure is recommended by the Pharmacy Quality Alliance ${ }^{37}$ and used by CMS in its rating of an insurance plan. ${ }^{38}$ Adherence was classified into 5 mutually exclusive groups (supplemental eAppendix 1 , available with this article at JNCCN.org).

\section{External Environment Factors}

These time-invariant external environment factors were measured at baseline. This domain included SEER region, county metropolitan status, and percentage of cardiologists and oncologists in the county. This study also controlled for time $\left(t_{1}-t_{6}\right)$ to better reflect changes associated with time in treatment practices.

\section{Statistical Analyses}

Unadjusted subgroup differences in time-invariant characteristics between cancer and noncancer categories by sex (6 groups) were tested with chi-square statistics. Our preliminary analyses indicated that there were significant group differences in age, race/ethnicity, concordant and discordant physical health conditions, mental health conditions, SEER region, and index year between the categories. Therefore, inverse probability treatment weights (IPTWs) were derived using the multinomial logistic regression on cancer and noncancer categories, with sex, age, race/ethnicity, SEER region, and index year as independent variables; these weights were used when modeling expenditures to adjust for the differences in these variables between cancer and noncancer cohorts. The weighting enabled us to balance the differences among cancer and noncancer cohorts. Supplemental eAppendix 2 summarizes the findings from the multinomial logistic regression used to calculate IPTW.

Because CAD-related healthcare expenditures were measured every 120 days during the preindex and postindex periods, each individual had 6 observations. These observations were not independent, and therefore the authors used generalized linear mixed models (GLMMs) with gamma distribution and log-link to analyze adjusted relationships between cancer and noncancer groups and CAD-related healthcare expenditures. This is the most commonly used approach in previous cost analyses. ${ }^{39,40}$ These GLMMs included predisposing, enabling and need factors, external environmental characteristics, and time.

\section{Results}

Characteristics of the Study Cohorts Before and After IPTW Adjustment

The study cohort comprised 46,332 elderly FFS Medicare beneficiaries with preexisting CAD (12,095 with cancer and 34,237 without cancer). After adjusting with IPTW, no significant differences were seen in independent variables between cancer diagnoses (Table 1).

Expenditures for $t_{1}, t_{2}$, and $t_{3}$ were aggregated to represent the preindex period, and expenditures for $t_{4}, t_{5}$, and $t_{6}$ were aggregated to represent the postindex period (Table 2). CAD-related expenditures in the postindex period were approximately 3 times higher for men and women with CRC, 2 times higher for women with breast cancer, and 1.5 times higher for ment with prostate cancer. The postindex CAD-related expenditures for the noncancer group, in comparison, were similar to those in the preindex period.

\section{CAD-Related Expenditures Over Time by Cancer and} Noncancer Status

When time was included as an adjuster, the time coefficient was positive across all cancer groups, suggesting that CAD-related expenditures increased over time for all cancer groups (Figure 3). However, no such differences were observed for noncancer groups.

\section{Adjusted Relationships Between Cancer and CAD-related Healthcare Expenditures}

Total CAD-related expenditures are presented in Table 3 and inpatient and outpatient CAD-related expenditures 
Table 1. Unweighted and Weighted Percent of Selected Characteristics by Cancer Diagnosis Categories

Before IPTW (\%) for Cancer Groups

After IPTW (Weighted \%) for Cancer Groups

\begin{tabular}{|c|c|c|c|c|c|c|c|c|c|c|c|c|c|c|}
\hline Characteristics & Breast & $\begin{array}{l}\text { Colorectal } \\
\text { (Women) }\end{array}$ & $\begin{array}{l}\text { Colorectal } \\
\text { (Men) }\end{array}$ & Prostate & $\begin{array}{c}\text { None } \\
\text { (Women) }\end{array}$ & $\begin{array}{l}\text { None } \\
\text { (Men) }\end{array}$ & Sig $^{a}$ & Breast & $\begin{array}{l}\text { Colorectal } \\
\text { (Women) }\end{array}$ & $\begin{array}{l}\text { Colorectal } \\
\text { (Men) }\end{array}$ & Prostate & $\begin{array}{c}\text { None } \\
\text { (Women) }\end{array}$ & $\begin{array}{l}\text { None } \\
\text { (Men) }\end{array}$ & Sig $^{a}$ \\
\hline Age, $y$ & & & & & & & $\star \star \star$ & & & & & & & NS \\
\hline $68-70$ & 13.8 & 9.2 & 14.7 & 21.4 & 13.7 & 22.4 & & 17.0 & 16.6 & 16.7 & 16.5 & 16.8 & 16.9 & \\
\hline $71-74$ & 19.8 & 14.5 & 23.4 & 30.5 & 17.2 & 23.8 & & 20.7 & 20.8 & 20.7 & 20.6 & 20.6 & 20.6 & \\
\hline $75-79$ & 26.0 & 22.2 & 25.0 & 27.8 & 21.2 & 23.4 & & 22.8 & 23.5 & 23.4 & 23.0 & 23.1 & 22.9 & \\
\hline$\geq 80$ & 40.4 & 54.1 & 36.9 & 20.3 & 47.9 & 30.4 & & 39.5 & 39.2 & 39.2 & 39.9 & 39.5 & 39.6 & \\
\hline Race/Ethnicity & & & & & & & $\star \star \star$ & & & & & & & NS \\
\hline White & 82.5 & 78.7 & 82.8 & 82.7 & 75.0 & 77.6 & & 77.5 & 77.0 & 77.1 & 76.0 & 77.2 & 77.1 & \\
\hline African American & 9.4 & 11.2 & 4.9 & 7.6 & 10.4 & 5.7 & & 8.7 & 8.8 & 8.7 & 9.0 & 8.7 & 8.7 & \\
\hline Hispanic & 2.9 & 2.3 & 2.1 & 2.6 & 4.3 & 4.0 & & 3.7 & 3.6 & 4.1 & 4.2 & 3.9 & 4.0 & \\
\hline Other & 5.2 & 7.8 & 10.2 & 7.1 & 10.3 & 12.7 & & 10.0 & 10.6 & 10.0 & 10.8 & 10.2 & 10.2 & \\
\hline Concordant $\mathrm{PHC}^{\mathrm{b}}$ & & & & & & & $\star \star \star$ & & & & & & & NS \\
\hline Yes & 95.5 & 96.4 & 95.4 & 94.6 & 94.0 & 92.4 & & 93.8 & 93.4 & 94.0 & 94.3 & 93.9 & 93.9 & \\
\hline No & 4.5 & 3.6 & 4.6 & 5.4 & 6.0 & 7.6 & & 6.2 & 6.6 & 6.0 & 5.7 & 6.1 & 6.1 & \\
\hline Discordant $\mathrm{PHC}^{\mathrm{b}}$ & & & & & & & 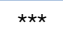 & & & & & & & \\
\hline Yes & 48.1 & 51.4 & 37.5 & 31.7 & 50.1 & 33.9 & & 43.2 & 43.9 & 43.4 & 43.9 & 43.5 & 43.8 & \\
\hline No & 51.9 & 48.6 & 62.5 & 68.3 & 49.9 & 66.1 & & 56.8 & 56.1 & 56.6 & 56.1 & 56.5 & 56.2 & \\
\hline $\mathrm{MHC}^{\mathrm{b}}$ & & & & & & & $\star \star \star ~$ & & & & & & & \\
\hline Yes & 13.0 & 13.1 & 8.9 & 5.7 & 15.2 & 9.3 & & 12.1 & 12.6 & 12.4 & 12.6 & 12.2 & 12.6 & \\
\hline No & 87.0 & 86.9 & 91.1 & 94.3 & 84.8 & 90.7 & & 87.9 & 87.4 & 87.6 & 87.4 & 87.8 & 87.4 & \\
\hline SEER region & & & & & & & $\star \star \star$ & & & & & & & NS \\
\hline Northeast & 24.1 & 26.3 & 24.0 & 20.0 & 22.7 & 18.9 & & 21.9 & 21.6 & 21.7 & 20.1 & 21.6 & 21.7 & \\
\hline South & 25.1 & 25.4 & 22.2 & 24.6 & 25.6 & 23.8 & & 24.9 & 24.5 & 24.7 & 25.2 & 24.7 & 24.5 & \\
\hline North-Central & 13.9 & 14.5 & 12.8 & 14.2 & 11.8 & 10.5 & & 12.1 & 11.5 & 12.1 & 12.8 & 12.0 & 11.9 & \\
\hline West & 36.9 & 33.8 & 41.0 & 41.1 & 39.9 & 46.8 & & 41.1 & 42.3 & 41.5 & 41.9 & 41.6 & 41.9 & \\
\hline Index year & & & & & & & $\star \star$ & & & & & & & NS \\
\hline 2008 & 24.0 & 25.1 & 24.9 & 24.6 & 23.9 & 23.4 & & 24.1 & 25.9 & 23.7 & 22.8 & 23.9 & 24.7 & \\
\hline 2009 & 24.5 & 23.9 & 23.8 & 25.1 & 23.8 & 24.7 & & 23.8 & 23.7 & 24.9 & 23.6 & 24.2 & 24.2 & \\
\hline 2010 & 25.4 & 25.6 & 25.3 & 23.8 & 26.1 & 24.8 & & 26.0 & 25.7 & 25.6 & 25.5 & 25.4 & 25.2 & \\
\hline 2011 & 26.1 & 25.3 & 25.9 & 26.5 & 26.3 & 27.1 & & 26.2 & 24.7 & 25.7 & 28.1 & 26.6 & 25.9 & \\
\hline
\end{tabular}

Time-invariant characteristics included cancer diagnosis categories, age, race/ethnicity, poverty status, high school education, concordant and discordant physical health conditions, severe mental illness, SEER region, and county-level characteristics. Time-variant characteristics included tobacco use, alcohol use, depression, anxiety, routine followup with primary care physician and/or cardiologist, and donut hole.

Abbreviations: CAD, coronary artery disease; IPTW, inverse probability treatment weighting; MHC, mental health conditions; NS, nonsignificant; PHC, physical health conditions; sig, significance.

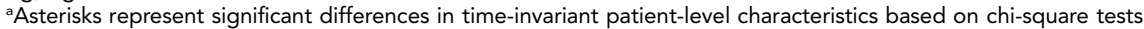

${ }^{b}$ Concordant physical health conditions consisted of diabetes, hyperlipidemia, hypertension, stroke, cardiac arrhythmia, and congestive heart failure. Discordant physical health conditions consisted of arthritis, asthma, chronic obstructive pulmonary disease, osteoporosis, dementia, human immunodeficiency virus, and hepatitis. Mental health conditions included anxiety, depression, severe mental illness (schizophrenia, bipolar disorder, psychoses).

$\star \star \star P<.001 ;{ }^{\star *} .001 \leq P<.01 ;{ }^{\star} .01 \leq P<.05$. Column percentages are reported.

are presented in Table 4. CAD-related healthcare expenditure comparisons by cancer status, sex, and cancer type are detailed as follows.

\section{Cancer Versus No Cancer}

Patients with breast, colorectal, or prostate cancer had higher outpatient and total CAD-related expenditures compared with their noncancer counterparts. Inpatient expenditures were significantly higher for CRC, but not for breast or prostate cancer, compared with their noncancer counterparts.

\section{Men Versus Women}

Women with CRC or no cancer had lower total inpatient, outpatient, and CAD-related expenditures compared with men with CRC or no cancer, respectively. 
Table 2. CAD-Related Expenditures Adjusted With Inverse Probability Treatment Weights

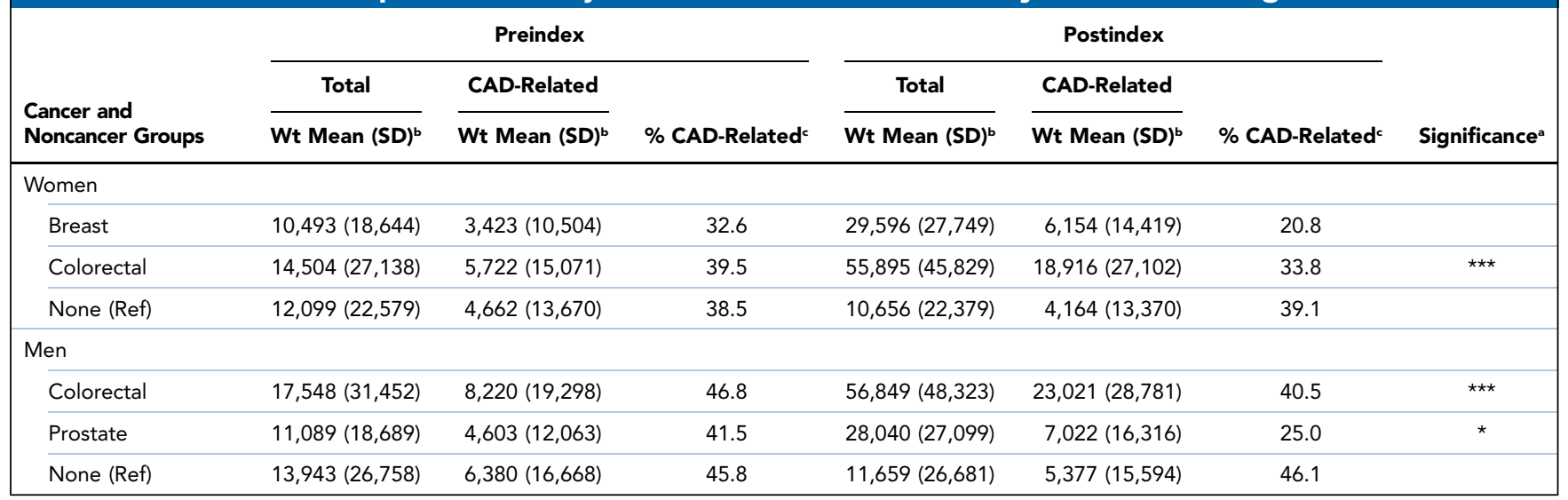

Abbreviations: CAD, coronary artery disease; $\mathrm{Wt}$, weighted.

asterisks represent significant differences in cancer and noncancer categories. Significance was derived from unadjusted generalized linear model with gamma distribution and log-link. The analysis included 6 repeated observations.

${ }^{b}$ All expenditures reported in 2012 USD.

cPercentage CAD-related $=\frac{\text { CAD- related expenditures }}{\text { Total expenditures }} \times 100$

${ }^{* \star *} P<.001 ;{ }^{* \star} .001 \leq P<.01 ;{ }^{*} .01 \leq P<.05$.

\section{Cancer Type}

Both men and women with CRC had higher inpatient and total CAD-related expenditures compared with men with prostate cancer and women with breast cancer, respectively.

\section{Relationship Between Other Independent Variables} and Expenditures

Factors associated with significantly increased expenditures included age $\geq 80$ years, concordant and discordant physical health conditions, mental health conditions, higher CAD severity, tobacco use, alcohol use, visit to primary care physician or cardiologist, and nonadherence to one or both medication classes (for those using both medication classes; supplemental eAppendix 1).

\section{Discussion}

This is the first study to estimate short-term CADrelated expenditures among cancer and noncancer
A

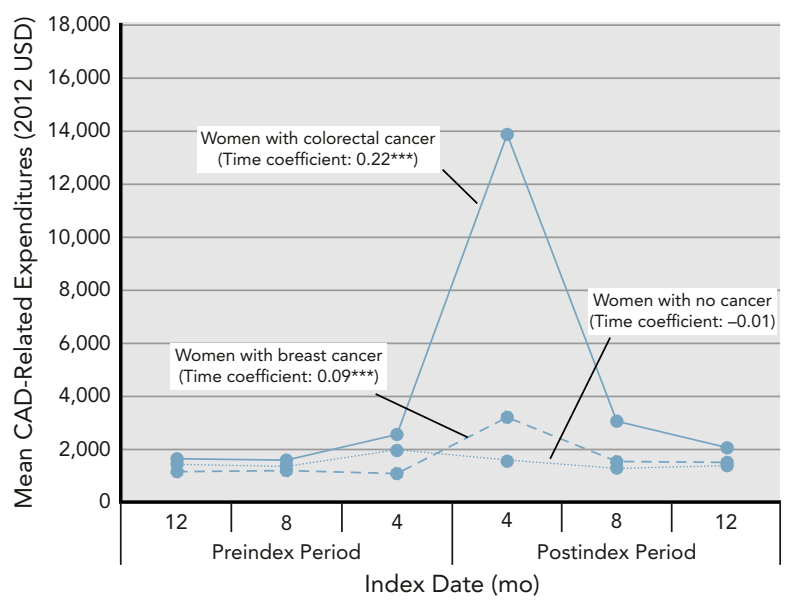

B

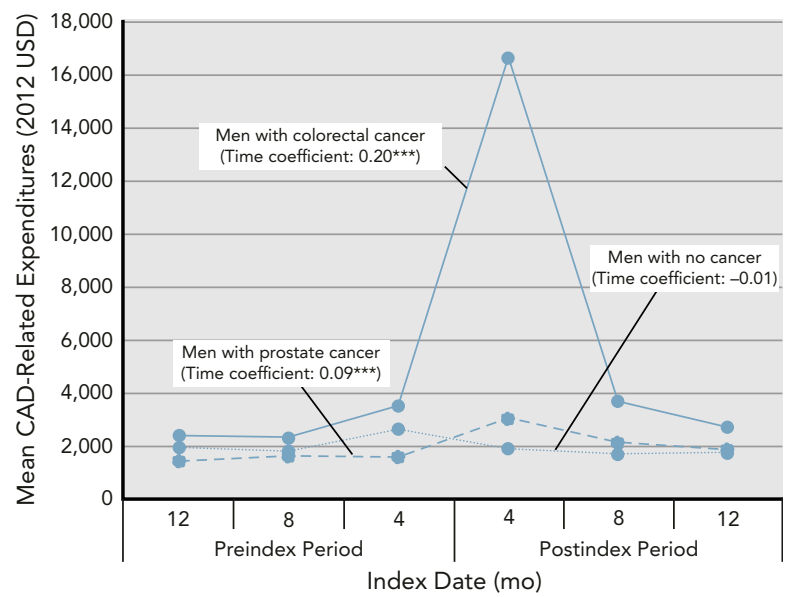

Figure 3. Weighted average CAD-related expenditures among cancer and noncancer cohorts in (A) women and (B) men during 120-day intervals. Based on 46,332 elderly fee-for-service Medicare beneficiaries with preexisting CAD between 2008 and 2011 (cancer cohort: $n=12,095$; noncancer cohort: $n=34,237)$. Individuals with incident breast, colorectal, or prostate cancer were derived from the SEER registries, and individuals with no cancer were derived from the $5 \%$ noncancer sample from the SEER region. Weights were derived using the inverse probability treatment weights approach. Asterisks represent significant differences in cancer and noncancer groups.

Abbreviation: CAD, coronary artery disease.

${ }^{\star * \star} P<.001 ;{ }^{* \star} .001 \leq P<.01 ;{ }^{*} .01 \leq P<.05$. 


\begin{tabular}{|c|c|c|c|c|}
\hline Cancer Diagnosis Categories & Coefficient & SE & $P$ Value & $\%$ Change $^{a}$ \\
\hline Breast & 0.13 & 0.04 & .002 & $14 \%$ \\
\hline Colorectal (women) & 0.92 & 0.05 & .000 & $151 \%$ \\
\hline \multicolumn{5}{|c|}{ Cancer vs noncancer (Ref: none [men]) } \\
\hline Colorectal (men) & 0.97 & 0.05 & .000 & $164 \%$ \\
\hline Prostate & 0.11 & 0.04 & .008 & $12 \%$ \\
\hline Intercept & 4.25 & 0.14 & & \\
\hline \multicolumn{5}{|l|}{ Sex differences (Ref: none [men]) } \\
\hline Colorectal (women) & -0.29 & 0.07 & .000 & $-25 \%$ \\
\hline Intercept & 5.22 & 0.15 & & \\
\hline \multicolumn{5}{|c|}{ Cancer type differences (Ref: breast) } \\
\hline Colorectal (women) & 0.79 & 0.06 & .000 & $55 \%$ \\
\hline Intercept & 4.93 & 0.15 & & \\
\hline \multicolumn{5}{|c|}{ Cancer type differences (Ref: prostate) } \\
\hline Colorectal (men) & 0.85 & 0.06 & .000 & $57 \%$ \\
\hline Intercept & 5.22 & 0.15 & & \\
\hline
\end{tabular}

Abbreviations: CAD, coronary artery disease; GLMMs, generalized linear mixed models.

apercent change for GLMMs was calculated as ( $\left.e^{\text {(intercept }+\beta)}-e^{\text {intercept }}\right) / e^{\text {intercept }}$.

FFS Medicare beneficiaries with preexisting CAD. In general, CAD accounted for a substantial portion of total expenditures before and after cancer diagnosis, and these expenditures were higher for those with cancer compared with those without. The authors speculate that part of the CAD-related expenditures among patients with cancer may result from cancer treatments. ${ }^{7,8}$ For patients undergoing cancer surgery, CAD may need to be stabilized using medical management, ${ }^{7}$ further adding to their overall CAD-related expenditures. Moreover, it is plausible that cancer may take precedence over $C A D$ management and impede the recommended care for $\mathrm{CAD}$, thereby increasing CAD-related complications ${ }^{9}$ and leading to higher CAD-related expenditures.

Notably, CAD-related expenditures were highest among patients with CRC compared with those with breast, prostate, or no cancer. Furthermore, CAD-related expenditures were highest during the 120-day interval immediately after CRC diagnosis. Most patients in our study had advanced-stage CRC (63.0\%), treatment of which consists of surgery and adjuvant chemotherapy (eg, 5-fluorouracil and capecitabine). ${ }^{41}$ This suggests that CAD-related expenditures may be higher among those with CRC due to chemotherapy-related cardiotoxicity.
Additionally, nonadherence to statins and ACEIs/ARBs/ $\beta$-blockers was significantly higher in patients with CRC who had undergone surgery $(81 \%)$. Nonadherence to these medications may increase the risk of CAD-related complications and hospitalizations, thereby increasing inpatient expenditures. ${ }^{42}$

Another noteworthy finding was that women had lower CAD-related expenditures compared with men. Chiha et $\mathrm{al}^{43}$ assessed the differences in CAD severity among men and women and noted that women were more likely to have normal coronary arteries or less severe disease than age-matched men. Although we controlled for severity of CAD with HCC, future research needs to explore whether the lower expenditures among women are because of sex-related differences in severity of CAD.

Finally, CAD-related expenditures increased over time for all cancer groups. Our findings indicated that expenditures were highest during the 120-day interval immediately after cancer diagnosis, suggesting that the period after cancer diagnosis may be crucial for CAD management.

\section{Policy Implications}

New bundled payment models and the Medicare Shared Savings Program use risk adjustment to calculate 


\begin{tabular}{|c|c|c|c|c|c|c|c|c|}
\hline \multirow[b]{2}{*}{ Cancer Diagnosis Categories } & \multicolumn{4}{|c|}{ Inpatient CAD-Related Expenditures } & \multicolumn{4}{|c|}{ Outpatient CAD-Related Expenditures } \\
\hline & Coefficient & SE & $P$ Value & $\%$ Change $^{a}$ & Coefficient & SE & $P$ Value & $\%$ Change $^{a}$ \\
\hline \multicolumn{9}{|c|}{ Cancer vs noncancer (Ref: none [women]) } \\
\hline Breast & 0.11 & 0.08 & .15 & $12 \%$ & 0.43 & 0.04 & .000 & $54 \%$ \\
\hline Colorectal (women) & 1.22 & 0.08 & .000 & $239 \%$ & 0.39 & 0.05 & .000 & $48 \%$ \\
\hline Intercept & 2.36 & 0.20 & & & 3.13 & 0.12 & & \\
\hline \multicolumn{9}{|c|}{ Cancer vs noncancer (Ref: none [men]) } \\
\hline Colorectal (men) & 1.25 & 0.08 & .000 & $249 \%$ & 0.41 & 0.06 & .000 & $51 \%$ \\
\hline Prostate & 0.10 & 0.07 & .152 & $11 \%$ & 0.27 & 0.04 & .000 & $31 \%$ \\
\hline Intercept & 2.71 & 0.20 & & & 3.47 & 0.11 & & \\
\hline \multicolumn{9}{|l|}{ Sex differences (Ref: none [men]) } \\
\hline None (women) & -0.35 & 0.06 & .000 & $-30 \%$ & -0.35 & 0.03 & .000 & $-30 \%$ \\
\hline Intercept & 2.71 & 0.20 & & & 3.47 & 0.11 & & \\
\hline \multicolumn{9}{|c|}{ Sex differences (Ref: colorectal [men]) } \\
\hline Colorectal (women) & -0.38 & 0.10 & .000 & $-32 \%$ & -0.37 & 0.07 & .000 & $-31 \%$ \\
\hline Intercept & 3.96 & 0.21 & & & 3.89 & 0.13 & & \\
\hline \multicolumn{9}{|c|}{ Cancer type differences (Ref: breast) } \\
\hline Colorectal (women) & 1.11 & 0.1 & .000 & $67 \%$ & -0.04 & 0.06 & .522 & $-4 \%$ \\
\hline Intercept & 3.58 & 0.21 & & & 3.52 & 0.13 & & \\
\hline \multicolumn{9}{|c|}{ Cancer type differences (Ref: prostate) } \\
\hline Colorectal (men) & 1.14 & 0.09 & .000 & $68 \%$ & 0.14 & 0.09 & .056 & $13 \%$ \\
\hline Intercept & 3.96 & 0.21 & & & 3.89 & 0.13 & & \\
\hline
\end{tabular}

Abbreviations: CAD, coronary artery disease; GLMMs, generalized linear mixed models.

apercent change for GLMM was calculated as $\left(\mathrm{e}^{\text {(intercept }+\beta)}-\mathrm{e}^{\text {intercept }}\right) / \mathrm{e}^{\text {intercept }}$.

expenditure benchmarks needed to provide care and obtain shared savings from the CMS. ${ }^{13,44}$ These valuebased frameworks have been designed to improve the quality and affordability of care. These frameworks aim to ensure that the cost of overall care, including treatment, interventions, and prescriptions, reflect the benefits for better quality of life. There are few notable value frameworks in oncology that account for each stakeholder's perspective. Collectively, our findings can help payers calculate these benchmark expenditures by adjusting for case mix of Medicare beneficiaries, specifically those with preexisting $\mathrm{CAD}$ and incident cancer. ${ }^{14-16}$ In addition, our findings can help capture the episodespecific contribution of individual risk factors (eg, age, sex, comorbidities, episode severity) to resource use, similar to risk models implemented by the PROMETHEUS Payment model. ${ }^{16,45}$ PROMETHEUS is a bundled payment model that uses algorithms to create episodes with relevant services. It helps determine appropriate reimbursement rates for payment for multiple medical conditions and procedures in an episode-of-care system. Currently, no specific payment models account for cancer and CAD, but available models such as PROMETHEUS can be tailored to specific patterns of resource use within CAD. Therefore, it is crucial to understand the extent to which a specific cancer contributes to CAD-related expenditures to implement these models. Based on our study findings, it is apparent that resource allocation for CAD-related expenditures should be higher for patients with CRC, followed by prostate and breast cancer.

The authors also found that CAD-related inpatient expenditures accounted for two-thirds of the overall CAD-related healthcare expenditures. Heart failure as a comorbidity can greatly diminish the patient's quality of life, limit the therapeutic dose of anticancer treatment, and significantly affect the patient's use of healthcare services, with frequent hospital readmissions. Although CMS has imposed penalties for potential hospital readmissions and preventable hospitalizations, such as inpatient admissions for angina without procedures, ${ }^{46}$ these may not be effective in patients with complex conditions such as CAD and cancer. In this context, future research needs to focus on collaborative care models, such as the patient-centered medical home, 
because such models have been shown to reduce inpatient use. ${ }^{47,48}$

\section{Strengths and Limitations}

This study adopted a longitudinal design and compared expenditures over time between cancer and noncancer groups. We also used statistical adjustment for selection bias in observed and unobservable characteristics. Use of Medicare FFS claims data enabled us to track individuals across various providers and settings, and calculate expenditures and measure variables for specific periods. The study also adjusted for a comprehensive list of factors that can influence CAD-related expenditures and included individuals with significant medical comorbidities.

Our findings cannot be generalized to all Medicare beneficiaries, because the study population is restricted to those residing in SEER regions and those with FFS Medicare plans. Furthermore, SEER-Medicare data are not developed for research purposes, and therefore have limitations associated with their use for estimating healthcare expenditures. There might be underestimation of CAD-related diagnosis, which in turn may undermine CAD-related expenditures for several reasons. It is possible that CAD diagnosis may be undercoded or misclassified in claims data, because these data are dependent on professional ICD coding. Furthermore, 1 year of follow-up may not be long enough to assess advanced-stage incident cancer, which might influence the link between increased spending and incidence cases. In addition, SEER-Medicare data do not capture all procedures performed. The overall cost burden of CAD in incident cancer cases might be an underestimate as a result of not including end-of-life care and broader expenditures, such as out-of-pocket costs or productivity issues. Finally, we were not able to control for family history, patient-level lifestyle health behaviors, knowledge, attitude, and preferences, or number of cancer-related complications, treatment-related adverse effects, and cost-related factors that may affect CADrelated expenditures.

\section{Conclusions}

Our findings showed that incident cancer diagnosis was associated with higher short-term CAD-related expenditures compared with patients without cancer. Specifically, inpatient expenditures for patients with CRC were considerably higher than outpatient expenditures, suggesting the need for greater emphasis on preventing cardiac events in the outpatient setting to reduce more expensive inpatient encounters. Future studies are needed to explore whether the emerging payment reforms and collaborative care models can lower costs while maintaining high-quality CAD care for patients with and without cancer.

Submitted February 1, 2018; accepted for publication August 20, 2018.

Author contributions: Study design: Chopra, Sambamoorthi. Data analysis: Chopra, Sambamoorthi. Manuscript preparation: Chopra. Critical review: Sambamoorthi. Feedback on manuscript: Dwibedi, Mattes, Tan, Findley.

Disclosures: The authors have not received any financial consideration from any person or organization to support the preparation, analysis, results, or discussion of this article.

Disclaimer: Research reported in this publication was supported by the National Institute of General Medical Sciences of the NIH (U54GM104942). The content is solely the responsibility of the authors and does not necessarily represent the official views of the $\mathrm{NIH}$.

Correspondence: Ishveen Chopra, PhD, MBA, Department of Pharmaceutica Systems and Policy, West Virginia University, Robert C. Byrd Health Sciences Center, Box 9510, Morgantown, WV 26506-9510. Email: ishveenkc@gmail.com

\section{References}

1. Dieleman JL, Baral R, Birger M, et al. US spending on personal health care and public health, 1996-2013. JAMA 2016;316:2627-2646.

2. Druss BG, Marcus SC, Olfson M, et al. Comparing the national economic burden of five chronic conditions. Health Aff (Millwood) 2001; 20:233-241.

3. Tarride JE, Lim M, DesMeules M, et al. A review of the cost of cardiovascular disease. Can J Cardiol 2009;25:e195-202.

4. Gerteis J, Izrael D, Deitz D, et al. Multiple chronic conditions chartbook: 2010 medical expenditure panel survey data. Rockville, MD: Agency for Healthcare Research and Quality: 2014

5. Fillenbaum GG, Pieper CF, Cohen HJ, et al. Comorbidity of five chronic health conditions in elderly community residents: determinants and impact on mortality. J Gerontol A Biol Sci Med Sci 2000;55:M84-89.

6. Koene RJ, Prizment AE, Blaes A, et al. Shared risk factors in cardiovascular disease and cancer. Circulation 2016;133:1104-1114.

7. Krone RJ. Managing coronary artery disease in the cancer patient. Prog Cardiovasc Dis 2010;53:149-156.

8. Herrmann J, Lerman A, Sandhu NP, et al. Evaluation and management of patients with heart disease and cancer: cardio-oncology. Mayo Clin Proc 2014;89:1287-1306.

9. Piette JD, Kerr EA. The impact of comorbid chronic conditions on diabetes care. Diabetes Care 2006;29:725-731.

10. Nichols GA, Bell TJ, Pedula KL, et al. Medical care costs among patients with established cardiovascular disease. Am J Manag Care 2010;16:e86-93.

11. Distribution of Medicare Beneficiaries by Eligibility Category. Henry J Kaiser Family Foundation website. Available at: http://kff.org/medicare/ state-indicator/distribution-of-medicare-beneficiaries-by-eligibilitycategory-2/. Accessed May 27, 2016.

12. Wakim R, Ritchey M, Hockenberry J, et al. Geographic variations in incremental costs of heart disease among Medicare beneficiaries, by type of service, 2012. Prev Chronic Dis 2016;13:E180.

13. Episode Payment Models: General Information. Centers for Medicare \& Medicaid Services website. Available at: https://innovation.cms.gov/ initiatives/epm. Accessed January 20, 2017

14. A Framework for Alternative Payment Models. Center for Healthcare Quality \& Payment Reform website. Available at: http:// www.chqpr.org/. Accessed January 8, 2017.

15. CMS' Value-Based Programs. Available at: https://www.cms.gov/ Medicare/Quality-Initiatives-Patient-Assessment-Instruments/ValueBased-Programs/Value-Based-Programs.html. Accessed January 6, 2017

16. O'Byrne TJ, Shah ND, Wood D, et al. Episode-based payment: evaluating the impact on chronic conditions. Medicare Medicaid Res Rev 2013;3:pii: mmrr.003.03.a07. 
17. Cancer Stat Facts. National Cancer Institute. Surveillance, Epidemiology, and End Results Program website. Available at: http://seer.cancer.gov/ statfacts. Accessed March 18, 2016

18. Doyle JJ, Neugut Al, Jacobson JS, et al. Radiation therapy, cardiac risk factors, and cardiac toxicity in early-stage breast cancer patients. Int J Radiat Oncol Biol Phys 2007;68:82-93.

19. Gross CP, McAvay GJ, Guo Z, et al. The impact of chronic illnesses on the use and effectiveness of adjuvant chemotherapy for colon cancer. Cancer 2007:109:2410-2419.

20. Hall HI, Satariano WA, Thompson T, et al. Initial treatment for prostate carcinoma in relation to comorbidity and symptoms. Cancer 2002;95:2308-2315.

21. Jagsi R, Griffith KA, Koelling $T$, et al. Stroke rates and risk factors in patients treated with radiation therapy for early-stage breast cancer. J Clin Oncol 2006;24:2779-2785.

22. Otto SJ, Schröder FH, de Koning HJ. Risk of cardiovascular mortality in prostate cancer patients in the Rotterdam randomized screening trial. J Clin Oncol 2006;24:4184-4189.

23. Al-Kindi SG, Oliveira GH. Prevalence of preexisting cardiovascular disease in patients with different types of cancer: the unmet need for oncocardiology. Mayo Clin Proc 2016;91:81-83.

24. Andersen RM. Revisiting the behavioral model and access to medical care: does it matter? J Health Soc Behav 1995;36:1-10.

25. Andersen R, Newman JF. Societal and individual determinants of medical care utilization in the United States. Milbank Mem Fund Q Health Soc 1973;51:95-124.

26. Engels EA, Pfeiffer RM, Ricker W, et al. Use of Surveillance, Epidemiology, and End Results-Medicare data to conduct case-control studies of cancer among the US elderly. Am J Epidemiol 2011;174:860-870.

27. American Community Survey. Summary File Data. United States Census Bureau website. Available at: https://www.census.gov/programs-surveys/ acs/data/summary-file.html. Accessed March 30, 2016.

28. Area Health Resource Files (AHRF). Data.HRSA.gov website. Available at: https://data.hrsa.gov/topics/health-workforce/ahrf. Accessed March 2, 2016.

29. Condition Categories. Chronic Conditions Data Warehouse website. Available at: https://www.ccwdata.org/web/guest/condition-categories. Accessed May 18, 2016.

30. Whellan DJ, Greiner MA, Schulman KA, et al. Costs of inpatient care among Medicare beneficiaries with heart failure, 2001 to 2004. Circ Cardiovasc Qual Outcomes 2010;3:33-40.

31. Hall AE, Highfill T. Calculating Disease-Based Medical Care Expenditure Indexes for Medicare Beneficiaries: a Comparison of Method and Data Choices. Available at: http://www.nber.org/papers/w19720. Accessed June 17, 2016.

32. Consumer Price Index. Bureau of Labor Statistics website. Available at: https://www.bls.gov/cpi/. Accessed January 24, 2017

33. Pope GC, Kautter J, Ingber MJ, et al. Evaluation of the CMS-HCC Risk Adjustment Model: Final Report. Available at: https://www.cms.gov/ Medicare/Health-Plans/MedicareAdvtgSpecRateStats/downloads/ Evaluation_Risk_Adj_Model_2011.pdf. Accessed December 2, 2018.

34. Huxley RR, Woodward M. Cigarette smoking as a risk factor for coronary heart disease in women compared with men: a systematic review and meta-analysis of prospective cohort studies. Lancet 2011;378:1297-1305.
35. Djoussé L, Gaziano JM. Alcohol consumption and heart failure: a systematic review. Curr Atheroscler Rep 2008;10:117-120.

36. Choudhry NK, Shrank WH, Levin RL, et al. Measuring concurrent adherence to multiple related medications. Am J Manag Care 2009; 15:457-464

37. Nau DP. Proportion of Days Covered (PDC) as a Preferred Method of Measuring Medication Adherence. Available at: https://sep.yimg.com/ty/ cdn/epill/pdcmpr.pdf?t=1544201383\&. Accessed March 20, 2016.

38. Medicare 2016 Part C \& D Star Rating Technical Notes: First Plan Preview. Available at: https://www.cms.gov/Medicare/PrescriptionDrug-Coverage/PrescriptionDrugCovGenln/Downloads/2016Technical-Notes-Preview-1-v2015_08_05.pdf. Accessed October 17, 2016.

39. Pagano E, Petrelli A, Picariello R, et al. Is the choice of the statistical mode relevant in the cost estimation of patients with chronic diseases? An empirical approach by the Piedmont Diabetes Registry. BMC Health Serv Res 2015;15:582.

40. Mihaylova B, Briggs A, O'Hagan A, et al. Review of statistical methods for analysing healthcare resources and costs. Health Econ 2011;20: 897-916.

41. Floyd J, Morgan JP. Cardiotoxicity of Nonanthracycline Cancer Chemotherapy Agents. Available at: https://www.uptodate.com/contents/ cardiotoxicity-of-nonanthracycline-cancer-chemotherapy-agents? search=cardiotoxicity-of-nonanthracycline-cancer-chemotherapyagent\&source $=$ search_result\&selectedTitle $=1 \sim 150 \&$ usage_type $=$ default\&display_rank=1. Accessed December 30, 2015

42. Bitton A, Choudhry NK, Matlin OS, et al. The impact of medication adherence on coronary artery disease costs and outcomes: a systematic review. Am J Med 2013;126:357.e7-357.e27.

43. Chiha J, Mitchell P, Gopinath B, et al. Gender differences in the severity and extent of coronary artery disease. Int J Cardiol Heart Vasc 2015;8:161-166.

44. Shared Savings Program. CMS.gov. Available at: https://www.cms.gov/ Medicare/Medicare-Fee-for-Service-Payment/sharedsavingsprogram/ index.html?redirect=/SharedSavingsProgram/. Accessed February 4, 2017.

45. Hussey PS, Ridgely MS, Rosenthal MB. The PROMETHEUS bundled payment experiment: slow start shows problems in implementing new payment models. Health Aff (Millwood) 2011;30:2116-2124.

46. Hospital Readmissions Reduction Program (HRRP). CMS.gov. Available at: https://www.cms.gov/medicare/medicare-fee-for-service-payment/ acuteinpatientpps/readmissions-reduction-program.html. Accessed February 4, 2017

47. Maeng DD, Khan N, Tomcavage J, et al. Reduced acute inpatient care was largest savings component of Geisinger Health System's patient-centered medical home. Health Aff (Millwood) 2015;34:636-644.

48. Neilsen M, Beult L, Patel K, Nichols, LM. The patient-centered medical home's impact on cost and quality. Available at: https://www.pcpcc.org/ sites/default/files/resources/The\%20Patient-Centered\%20Medical\% $20 \mathrm{Home} \% 27$ s\%2Olmpact\%20on\%20Cost\%20and\%20Quality\%2C\% 20Annual\%20Review\%20of\%20Evidence\%2C\%202014-2015.pdf. Accessed February 4, 2017. 